\section{Animal Health Research Reviews}

\section{cambridge.org/ahr}

\section{Systematic Review}

Cite this article: Wisener LV, Sargeant JM, O'Connor AM, O'Sullivan TL, McEwen SA, Nwosu A, Rossi TM (2019). Non-antibiotic approaches for disease prevention and control in beef and veal production: a scoping review. Animal Health Research Reviews 20, 128-142. https://doi.org/10.1017/S1466252319000252

Received: 4 July 2019

Revised: 30 November 2019

Accepted: 3 December 2019

\section{Key words:}

Antibiotic stewardship; beef; non-antibiotic approaches; scoping review; veal

\section{Author for correspondence:}

Lee V. Wisener, Department of Population

Medicine, Ontario Veterinary College,

University of Guelph, Guelph,

Ontario N1G 2W1, Canada.

E-mail: Iwisener@uoguelph.ca

\title{
Non-antibiotic approaches for disease prevention and control in beef and veal production: a scoping review
}

Lee V. Wisener ${ }^{1,2}$ (D), Jan M. Sargeant ${ }^{1,2}$ (D) Annette M. O'Connor ${ }^{3}$ (D),
Terri L. O'Sullivan ${ }^{1}$, Scott A. McEwen ${ }^{1}$, Andrea Nwosu ${ }^{1}$ and Tanya M. Rossi ${ }^{1}$

${ }^{1}$ Department of Population Medicine, Ontario Veterinary College, University of Guelph, Guelph, Ontario N1G 2W1, Canada; ${ }^{2}$ Centre for Public Health and Zoonoses, University of Guelph, Guelph, Ontario N1G 2W1, Canada and

${ }^{3}$ Department of Veterinary Diagnostic and Production Animal Medicine, lowa State University College of Veterinary Medicine, Ames, IA 50011, USA

\begin{abstract}
Livestock producers are encouraged to reduce the use of antibiotics belonging to classes of medical importance to humans. We conducted a scoping review on non-antibiotic interventions in the form of products or management practices that could potentially reduce the need for antibiotics in beef and veal animals living under intensive production conditions. Our objectives were to systematically describe the research on this broad topic, identify specific topics that could feasibly support systematic reviews, and identify knowledge gaps. Multiple databases were searched. Two reviewers independently screened and charted the data. From the 13,598 articles screened, 722 relevant articles were charted. The number of relevant articles increased steadily from 1990. The Western European research was dominated by veal production studies whereas the North American research was dominated by beef production studies. The interventions and outcomes measured were diverse. The four most frequent interventions included non-antibiotic feed additives, vaccinations, breed type, and feed type. The four most frequent outcomes were indices of immunity, non-specific morbidity, respiratory disease, and mortality. There were seven topic areas evaluated in clinical trials that may share enough commonality to support systemic reviews. There was a dearth of studies in which interventions were compared to antibiotic comparison groups.
\end{abstract}

\section{Introduction}

Antimicrobial resistance (AMR) poses a threat to the health and wellbeing of humans and livestock (Laxminarayan et al., 2014). The World Health Organization (WHO), the World Organization for Animal Health (OIE), and the Food and Agriculture Organization of the United Nations (FAO) have all published statements identifying antimicrobial use in humans and animals as the main driver of AMR, and have called for a worldwide effort to reduce inappropriate and unnecessary antimicrobial use in all sectors (WHO, 2012; FAO, 2016; OIE, 2016).

The consequences of AMR in humans with serious infections are more severe when pathogens are resistant to antimicrobials of medical importance, particularly those of critical importance, because there exist limited or no alternative treatment options (WHO, 2018). Antibiotic classes have been categorized according to their importance for human health by the WHO (2018) and importance for animal health by the OIE (2015). These categorizations can be used to prioritize strategies to contain AMR, such as improved antibiotic stewardship. For example, WHO has developed guidelines that recommend certain restrictions on use of medically important antibiotics in non-human sectors (WHO, 2017). Antibiotics belonging to classes of medical importance to humans are used in livestock to treat ill animals, individually or in groups, or to prevent infections in vulnerable animals (Cameron and McAllister, 2016; CDDEP, 2015; WHO, 2018).

Individual nations are responding to the call for reduced antibiotic use in livestock through various regulations and industry guidelines. For example, in Canada, regulations imposed in December 2018 require veterinary oversight for administration by injection or by addition to feed or water all antibiotics belonging to classes of medical importance to humans, thereby eliminating their 'over-the-counter' use (Government of Canada, 2018). The US Food and Drug Administration Center for Veterinary Medicine promotes the prudent use of antibiotics belonging to classes of medical importance to humans in livestock by requiring their use be limited to purposes for assuring animal health and be administered with veterinary oversight. The use of medically important antibiotics in healthy animals for production purposes was prohibited by 2017 in the USA (US FDA, 2017). 
In beef production, antibiotics belonging to classes of medical importance to humans are most commonly used in veal calves to prevent and treat diarrhea, in beef calves or stocker cattle newly arrived to feedlots to prevent and treat respiratory infections, and in finishing feedlot cattle to prevent liver abscesses (Ribble et al., 2010; Reinhardt and Hubbert, 2015; Sneeringer et al., 2015; Amachawadi and Nagaraja, 2016; Cameron and McAllister, 2016). The rationale for the use of antibiotics in beef cattle and veal calves to treat or prevent infections caused by bacteria and other microbes stems from the complex polymicrobial nature of bovine infections (Hodgins et al., 2002; Hässig and Kretschmar, 2016). For example, in cases of bovine respiratory disease (BRD), the upper respiratory tract may first be infected and immune-compromised by a viral infection followed by a pulmonary infection of bacteria normally carried in the nasopharynx (Hodgins et al., 2002). A reduction in the use of antibiotics without compromising production efficiencies requires a comprehensive approach to the multiple modifiable risk factors that lead to beef and veal cattle infections that are currently prevented or treated with medically important antibiotics (Ribble et al., 2010). Management practices can potentially reduce the need for antibiotic therapy through several pathways, including ensuring passive immunoglobulin transfer to calves via adequate good quality colostrum intake; reducing stress at weaning, during transportation and immediately after relocation; and reducing exposure to viral and bacterial pathogens by limiting the mixing of animals from different sources (Sanderson et al., 2008; Pardon et al., 2015). Products in the form of vaccines, nonantibiotic feed additives, or non-antibiotic medications may enhance health and potentially the need for antibiotics. Further, the prevalence and severity of liver abscesses is generally inversely proportional to the level of dietary roughage or neutral detergent fiber content in beef cattle diets, and so dietary alterations could also reduce the need for antibiotic use (Nagaraja and Lechtenberg, 2007; Hernández et al., 2014; Amachawadi and Nagaraja, 2016).

Scoping reviews in the agriculture and agri-food sector are a relatively new method of knowledge synthesis (Pham et al., 2014). In a scoping review of scoping reviews, Pham et al. (2014) reported that $1.2 \%$ of the 344 scoping reviews identified were on agriculture and agri-food topics. The purpose of scoping reviews is to systematically map the literature with regard to the extent, range, and nature of the existing research in a particular topic area (Arksey and O'Malley, 2005; Levac et al., 2010). In addition, scoping reviews are useful as preliminary 'reconnaissance' to investigate the feasibility of undertaking a full systematic review and to identify gaps in existing research (Arksey and O'Malley, 2005; Levac et al., 2010). In contrast, systematic reviews aim to address a specific research question by collating all of the evidence that fits pre-specified eligibility criteria while minimizing bias by using explicit, systematic methods (Higgins and Green, 2011). Scoping reviews are descriptive and broader in nature than systematic reviews (Arksey and O'Malley, 2005). A scoping review of nonantibiotic approaches to beef and veal production at this time of increased attention to antibiotic stewardship may help researchers interested in advancing knowledge of alternative approaches by indicating research areas that could be subject to formal systematic reviews or merit further research. In addition, such a scoping review could illuminate current gaps in the research on nonantibiotic approaches to production for beef industry professionals, beef researchers, and research funding agencies.

The objectives of this scoping review were 3-fold: first, to examine and describe the range and nature of research on non- antibiotic approaches that may ultimately reduce the need for medically important antibiotics to prevent, control, or treat illnesses in beef and veal production; second, to identify areas where the available literature may support systematic reviews that could summarize the effect of specific non-antibiotic approaches within the broader topic area; and third, to identify knowledge gaps where additional primary research might provide valuable insight into the effectiveness of different specific nonantibiotic approaches.

\section{Methods}

Our methods followed the scoping review framework as described by Arkesy and O'Malley with some modifications (Arksey and O'Malley, 2005). A protocol was not registered for this scoping review and its reporting follows the PRISMA-ScR (Preferred Reporting Items for Systematic reviews and Meta-Analyses extension for Scoping Reviews) guidelines for the reporting of scoping reviews (Tricco et al., 2018).

Our review question was as follows: What is the nature of the primary research literature published since 1990 that measures a health outcome and evaluates non-antibiotic interventions (i.e. products and management practices) to prevent or control bacterial and viral illnesses, which therefore might reduce the need for medically important antibiotics to be used in beef and veal production in North America and other regions and countries with similar production conditions? We included viral illnesses, based on the proposition that preventing viral infections may reduce the need to treat secondary bacterial infections. We make the assumption that some non-antibiotic interventions have the potential to improve animal health in the face of infectious disease challenges thereby ultimately reducing the need for antibiotics. However, our objective was to describe the literature, and summarizing or otherwise indicating the reported efficacy of various interventions therefore was beyond the scope of this review. An assessment of the quality or risk of bias in the included studies was also beyond our scope. In this paper, we followed the definitions for disease prevention and control as given by the American Veterinary Medical Association (AVMA) (2019) and the United States Government Accountability Office (US GAO-11-801 report) in which prevention of disease at the population level is the administration of an intervention to a group of animals, none of which have evidence of infection or disease, in situations where disease is likely to occur without the intervention. Whereas, disease control refers to the administration of the intervention to a group of animals containing some individuals that exhibit clinical disease or infection with the intention of reducing the risk of further disease in the group.

\section{Expert stakeholder engagement}

The amount of literature worldwide on this broad topic was potentially very extensive. Consequently, we sought to focus this scoping review on the body of literature pertaining to nonantibiotic approaches most relevant to intensive beef production. The goal of the expert stakeholder engagement process was to inform the scope of this review. The stakeholder engagement included five specific objectives: first, to identify the countries or regions with similar intensive beef industries to those of Canada; second, to rate the importance of various antimicrobial types to antimicrobial stewardship in the beef industry (e.g. antibiotics belonging to medically important classes, ionophores, 
anticoccidials, and anthelmintics); third, to rate the importance to Canadian beef producers of interventions, management practices, and outcomes reported in research; four, to identify any additional interventions or outcomes not included in the initial lists; and finally, to identify other experts who should be consulted. An anonymous online survey in Survey Monkey was used to gather information from expert stakeholders working in Canadian beef industry associations (national and provincial), provincial government representatives, and scientists in Agriculture and Agri-Food Canada beef research centers and in Canadian universities engaged in beef agricultural and/or veterinary research. Survey respondents could select from a list of options for a particular question and/or respond in an open-ended format (Supplementary Appendix 1). We assumed that the stakeholder responses addressing the Canadian beef industry would apply similarly to the USA and other countries with intensive beef production. The most common responses and suggested additional responses were used to inform the parameters of the search, eligibility criteria, and data items for extraction. Ethics approval was not necessary as the survey results were used to inform the review process rather than as a reported finding of the review.

\section{Eligibility criteria}

English-language publications and unpublished evidence reported since 1990 were eligible information sources, as these were considered most likely to reflect research that was conducted under modern beef and veal production conditions similar to those in USA and Canada. Eligible countries or regions for sources of information included North America including Mexico, United Kingdom, Western and Eastern Europe, Russia, Australia, New Zealand, Brazil, Argentina, and Uruguay. Journal articles and unpublished sources such as theses, conference proceedings, and technical reports were included if they described primary research such as clinical trials (i.e. natural exposures), challenge trials (i.e. deliberate exposure), or observational studies, and if the study evaluated non-antibiotic interventions in the form of products or management practices that may improve the health of US and Canada breeds or cross-breeds of beef or veal animals, and if they measured an outcome of interest. Trials and observational studies reported within outbreak and case report articles were also eligible. For purposes of this review, 'intervention' also included both modifiable and non-modifiable risk factors such as breed, maternal antibody, environment, and housing. Outcomes of interest were identified $a$ priori and informed by our stakeholders. These outcomes were primarily restricted to bacterial or viral diseases; consequently studies evaluating other etiologies were excluded. In addition, though not strictly a health outcome, we included treatment cost as this was of particular interest to the stakeholders. Non-English language sources of information were excluded. The relevance screening form is available in Supplementary Appendix 2.

\section{Information sources}

An ad hoc search in Google to identify 'ideal papers' that met the inclusion criteria for our search was conducted to aid in the development and validation of the search strategy. A total of 25 ideal papers' were identified, describing a variety of non-antibiotic interventions and management practices studied in trials or observational studies.
Table 1. Data platform and database information sources used in the scoping review search on non-antibiotic approaches for disease prevention and control in beef and veal production

\begin{tabular}{ll}
\hline $\begin{array}{l}\text { Data } \\
\text { platform }\end{array}$ & Databases \\
\hline ProQuest & $\begin{array}{l}\text { Agricultural journals, ABI/INFORM (trade \& industry, } \\
\text { Global), Canadian Business \& Current Affairs (Science \& } \\
\text { Technology, Business, Current Affairs, Social Sciences, } \\
\text { History, Health \& Medicine, Literature \& Language, } \\
\text { Arts), Dissertations \& theses (A\&l, Social Sciences, } \\
\text { Science \& Technology, Health \& Medicine), } \\
\text { Dissertations \& Theses University of Guelph, Abstracts } \\
\text { in Virology and AIDS, Toxicology, Genetics, } \\
\text { Biotechnology Research, Industrial and Applied } \\
\text { Microbiology, and Bacteriology }\end{array}$ \\
\hline ProQuest & AGRICOLA \\
\hline ProQuest & MEDLINE, PubMed (not MEDLINE) \\
\hline $\begin{array}{l}\text { Web of } \\
\text { Science }\end{array}$ & Core Collection \\
\hline $\begin{array}{l}\text { Web of } \\
\text { Science }\end{array}$ & MEDLINE \\
\hline Web of & Current Contents Connect \\
\hline
\end{tabular}

The primary reviewer (LW) conducted the scoping review database search from 14 to 18 October 2016, using two data platforms, ProQuest and Web of Science, which incorporate multiple databases (Table 1). The data platform CAB Direct was originally targeted for inclusion, but was not used due to technical difficulties. Additional unpublished articles were identified through the Google search engine in a search conducted from 31 March to 7 April 2017. Beyond our contact with stakeholders regarding additional sources of articles, we did not attempt to contact authors to identify further sources.

Full texts of journal articles, theses, proceedings, or technical reports were obtained for relevant citations through the University of Guelph library resources, through Google, or using author requests via the researcher social networking site ResearchGate.

\section{Search}

The search was filtered by language (English), date of publication (from 1990), and by location filters for eligible countries if available. Additional filters were applied as available through the data platform and included source and document type (i.e. article, proceedings paper, meeting abstract, thesis, and review), subject or research areas and $\mathrm{MeSH}$ headings or qualifiers. No limits were applied as to where the search terms appeared (i.e. title, abstract, or full text). Citations were imported into the reference manager software EndNote (Clarivate Analytics, Philadelphia, USA). Removal of exact match duplicates was conducted in EndNote. Further deduplication based on close matches was conducted using the systematic review software DistillerSR (Evidence Partners, Ottawa, Canada).

The search included terms related to the specific cattle populations of interest (i.e. veal calves, dairy calves, beef cows, beef calves, stockers, and feedlot cattle), as well as intervention terms in the form of products (e.g. vaccines, feed additives including the addition of specific dietary components, and medications) or in the form of management practices (e.g. biosecurity, housing, 
Table 2. Search terms for non-antibiotic approaches for disease prevention and control in beef and veal production

\begin{tabular}{|c|c|}
\hline Groupings & Search terms \\
\hline Population terms & $\begin{array}{l}\text { (cow-calf OR "beef calves" OR "grazing calves" OR "veal calves" OR "male dairy calves" OR "dairy beef steers" OR "stocker } \\
\text { cattle" OR "backgrounders" OR "feedlot cattle" OR "finishing cattle" OR "fattening cattle" OR "feeder cattle" OR "fattening } \\
\text { period" OR "finishing period" OR "feedlot finishing" OR "finishing steers" OR "fattening steers" OR "Holstein bulls" OR } \\
\text { "Holstein steers" OR "beef heifers" OR "feedlot heifers" OR "finishing heifers" OR "fattening heifers" OR "beef steers" OR } \\
\text { "feedlot calves" OR "beef herds" OR "feedlot animals" OR "Holstein calves" OR "feeder calves" OR "sale barn-origin calves" } \\
\text { OR "sale barn origin calves" OR "sales-barn origin calves" OR "sales barn origin calves" OR "beef cattle" OR "beef cows") }\end{array}$ \\
\hline Product intervention terms & $\begin{array}{l}\text { (vaccine OR vaccines OR "BVD vaccines" OR "BVDV vaccines" OR immunization OR vaccination OR "combination vaccines" OR } \\
\text { "clostridial vaccines" OR minerals OR "mineral substances" OR vitamins OR "organic acids" OR "amino acids" OR } \\
\text { "supplemental dietary protein" OR "supplemental dietary nitrogen" OR ammoniated OR "polyunsaturated fatty acids" OR } \\
\text { "plant polysaccharides" OR "animal polysaccharides" OR "plant extracts" OR "plant extract" OR "feed enzymes" OR } \\
\text { probiotics OR "DFM" OR "direct-fed microbials" OR "competitive exclusion products" OR "live cultures" OR "nasal probiotics" } \\
\text { OR "bacterial extracts" OR "biological cytokines" OR yeast OR prebiotics OR immunostimulants OR "antimicrobial peptides" } \\
\text { OR bacteriophages OR bacteriocins OR endolycins OR exolycins OR synbiotics OR "S. cerevisiae" OR hormones OR "egg yolk } \\
\text { antibodies" OR "inhibitors of pathogenicity" OR "inhibitors targeting pathogenicity" OR "Chinese herbal medicines" OR } \\
\text { "chemical synthetics" OR "ubenimex" OR "predatory bacteria" OR Optaflexx OR Ractopamine OR "Ractopamine } \\
\text { Hydrochloride" OR Zelante OR RumeNext OR "RumeNext B" OR "RumeNext - Beef" OR "Prime Purge" OR "Nutrisound" OR } \\
\text { "Organo Pro" OR "CONVERT Calf Care" OR "CONVERTTM Calf Care" OR "TWEEN 80" OR "Tween 80" OR surfactante OR } \\
\text { "hormone-like substances" OR nucleotides OR "nitric oxide" OR Bovinex OR homeopathics) }\end{array}$ \\
\hline $\begin{array}{l}\text { Management intervention } \\
\text { terms }\end{array}$ & 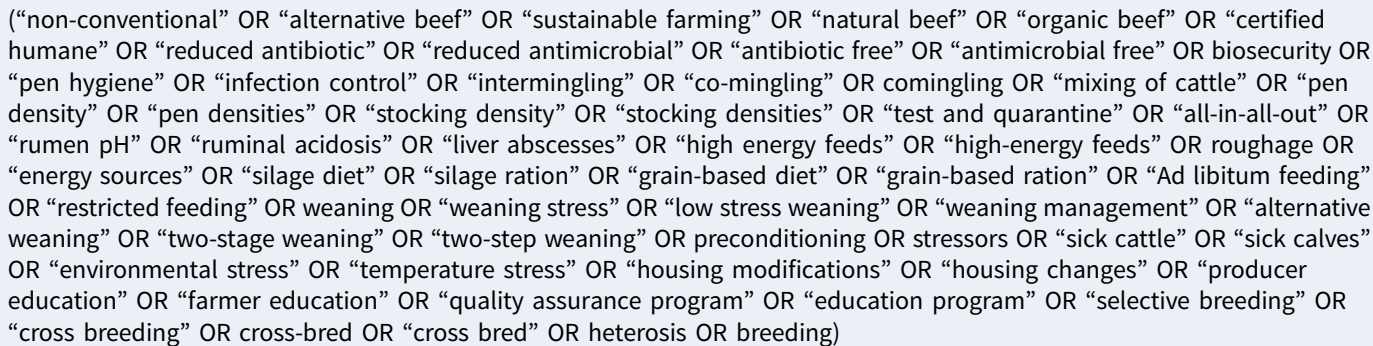 \\
\hline
\end{tabular}

A search string included the population terms and either the product intervention terms or the management intervention terms connected by the Boolean operator 'AND'.

and feed types) (Table 2). Search terms were combined using the Boolean operator 'OR' and grouped according to population terms and intervention terms. These two search term groupings were connected by the Boolean operator 'AND' in a search string. The search was conducted by the first author in consultation with a librarian. A single reviewer (LW) conducted the gray literature search in Google and screened the results for relevance. Because the Google platform cannot interpret long search strings, the search terms were presented to Google in short strings with approximately 100 hits examined for each search string; each small group of population terms were combined with each small group of intervention terms.

\section{Selection of sources of evidence}

The review team consisted of veterinary epidemiologists, one of whom acted as the primary reviewer, and two trained epidemiologists who served as second reviewers. Pre-testing for relevance screening was conducted on 500 articles based on the title and abstract. The data charting form was pre-tested on 60 full text articles. Two independent reviewers performed the screening and data extraction using forms created in DistillerSR. Disagreements were resolved by consensus or by a third reviewer. After pre-testing, the relevance screening and data charting questions did not change throughout the review, except on one occasion to simplify an ambiguous question distinguishing between experiments versus field trials. For purposes of this scoping review, field trials and experiments were combined into one category called clinical trials.

Study selection and data charting were conducted as separate steps. Each citation was initially screened for relevance based on information in the title and abstract. If sufficient information was lacking in the title and abstract alone, the citation was screened for relevance based on the full text.

\section{Data charting process}

Data charting was conducted in duplicate by the primary reviewer and a second reviewer working independently using a form in DistillerSR. Disagreements were resolved by consensus or by a third reviewer. The form to determine which variables to extract was developed, piloted, and updated iteratively by the veterinary epidemiologists. The form is available upon request. Data were charted from each article similarly; if more than one study was described, the data were collated so that all data charting was conducted at the article level. Data charting was conducted using the full text, and consequently data were only charted from citations for which the full text could be obtained. For purposes of reporting in this review 'article' refers to journal article, thesis, proceeding, or technical report.

\section{Data items}

We charted data on the study characteristics (e.g. study design, population settings, study location, study size, and year of publication) and trial characteristics (e.g. population type, intervention, comparison groups, and outcome(s) measured) (Table 3). The data charting was conducted using pre-selected response fields for all questions with an added text box for additional responses or clarification for the intervention type and outcomes measured. With one exception, we did not chart data that pertained to a common intervention among all the treatment group(s) (i.e. all 
Table 3. Description of data charting items for relevant journal articles, technical reports, proceedings, or theses

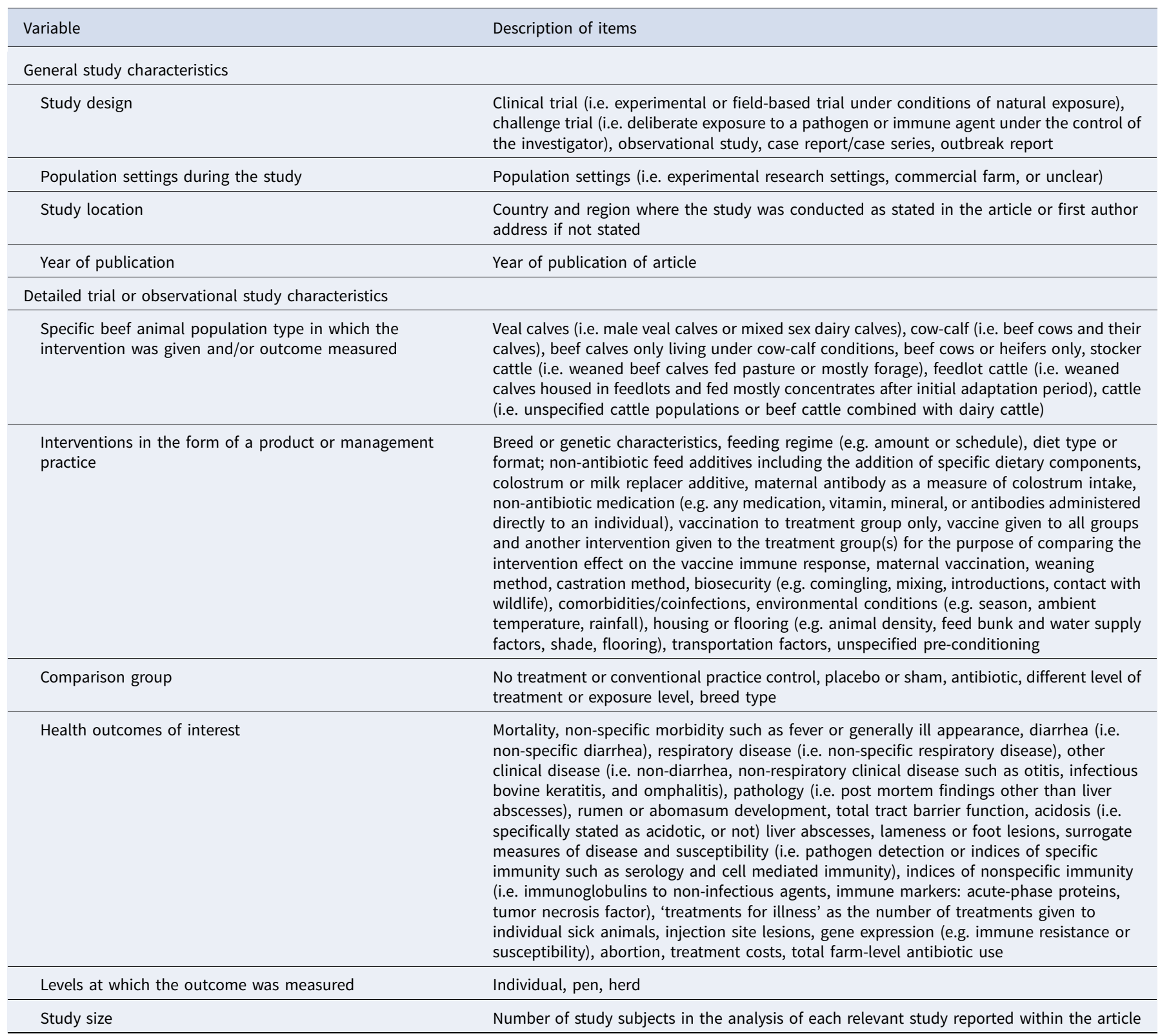

groups that received the intervention of interest and control groups). An exception was made for studies in which a vaccine was given to all groups and another intervention was given only to the treatment group(s) for the purpose of comparing the intervention effect on the vaccine immune response. Data for interventions were treated similarly. Examples included breed, which in some studies was treated as a modifiable intervention (e.g. genetics for disease resistance and survivability) (Williams et al., 1990) and in other studies was evaluated as a risk factor (e.g. beef calves of different breeds evaluated in a BRD vaccination trial) (Stilwell et al., 2008).

Data charted for comparison groups included a no treatment or conventional practice control group where one was clearly stated, otherwise the comparison group(s) was considered to be a different level or form of the treatment or exposure. For studies in which the treatment groups were given various levels or formats of the intervention of interest and comparisons were made among these groups, the data for the intervention type and the comparison groups were charted as 'different levels of treatment' (e.g. an article described the effects of various dietary levels of wet corn gluten feed on liver abscesses) (Hussein and Berger, 1995).

There was no attempt to distinguish between non-antibiotic interventions that were intended to prevent disease from those that were intended to treat or control disease because the distinction is often unclear in research reports. We defined the intervention type 'medication' to include any non-antibiotic medication, vitamin, mineral, antibody, or other treatment that was administered directly via injection or oral bolus to individual animals. The same medication given to the entire group of animals via their feed was charted as a feed additive.

Some studies reported the outcome 'treatment rate' referring to the number of treatment(s) given to individual sick animals, but since a measure of time was not included in the denominator, the measure of disease frequency most were referring to was a risk 
rather than a rate. For purposes of this review, we referred to the term as 'treatments for illness.' For purposes of this review, surrogate measures of disease and susceptibility included detection of infection and indices of specific immunity.

To meet our second objective of identifying feasible future systematic reviews, we identified topic areas for which there was commonality among clinical trials with regard to the population, intervention, and clinically important outcomes measured. Observational study designs, non-randomized clinical trials or randomized clinical trial (RCT) designs can be used in systematic reviews of interventions. However, the RCT is considered to have the best evidentiary value (Sargeant et al., 2014). For this reason, we chose to focus our second objective on clinical trials. Clinically important outcomes were defined after data charting and included mortality, non-specific morbidity, respiratory disease, diarrhea, liver abscesses, acidosis, and treatments for illness. Thus, not all outcomes of interest were considered clinically important outcomes. For example, infections with specific pathogens and indices of specific or non-specific immunity may not reliably predict clinical outcomes; consequently these outcomes were not included as clinically important outcomes (Fleming and Powers, 2012). Study results were not extracted, and no attempt was made to determine the direction of the effect of the outcome (e.g. if the intervention showed a favorable outcome), as that was beyond the scope of this review. The topic areas identified as potentially extensive enough for systematic review were those with a minimum of five clinical trials reporting similar interventions or types of intervention (e.g. specific respiratory disease vaccines, probiotics, medications, minerals, and feed types such as roughage content) and the same specific population in which the outcome was measured (e.g. veal calves and feedlot cattle) and at least one, but not necessarily the same, reported clinically important outcome.

\section{Synthesis of results}

The charted data were entered into a database in Stata 15.1 (College Station, Texas, USA). Descriptive statistics were compiled according to our stated data charting scheme for all study designs and were presented in the form of tables and figures. We presented detailed results for articles that reported clinical trials or observational studies so as to emphasize the literature with the greatest evidentiary value (Sargeant et al., 2014). For challenge trials, we presented details only for the types of challenges studied.

\section{Results}

\section{Expert stakeholder engagement}

Seventy-four experts received an invitation to the survey, of which 38 (51\%) responded. The stakeholder engagement process helped to inform the search strategy and the data charting items. No publications were suggested by the stakeholders that had not been captured in the search.

\section{Selection of sources of evidence}

There were 13,598 unique citations identified by the search that underwent relevance screening and 1110 (8\%) were assessed for relevance based on the full text. There were 722 full text articles considered eligible for data charting (Fig. 1). The majority of sources of evidence were full text published articles identified through the database searches. Theses, proceedings, and technical reports from the database sources represented $6 \%$ of the relevant evidence (Fig. 1). Interestingly, 11 of the 15 full text theses were identified through the Google search.

\section{Characteristics of sources of evidence}

Sixty-eight articles (9\%) described more than one study of the same design or different design within the same article. Among the 722 included articles, there were 752 studies described which comprised clinical trials $(n=439,61 \%)$, observational studies $(n=162,22 \%)$, and challenge trials $(n=151,21 \%)$.

The clinical trials and challenge trials were conducted largely using animals living under experimental farm settings $(n=363$, $83 \%)$ and $(n=148,98 \%)$ respectively, whereas the observational studies were conducted largely in animals living under commercial farm settings $(n=128,79 \%)$. Some articles included experimental and commercial settings and in 11 articles it was unclear if the farm settings were commercial or experimental. Among the articles in which the settings were clearly identified, the majority of the explicitly described beef populations (e.g. stockers, veal calves, feedlot cattle, beef calves, cow-calf pairs, and cow/heifers) were animals living under experimental settings $(83,81,75,73,62$, and $51 \%)$ respectively whereas, the unspecified cattle populations were largely animals living under commercial settings $(80 \%)$.

The majority of articles described clinical trials, challenge trials, and observational studies conducted in USA and Canada (74\%). The cattle populations most commonly studied in USA, Canada, and Australia/New Zealand were feedlot cattle, whereas in Western and Eastern Europe the cattle populations most often studied were veal calves (Table 4). In South American countries and Mexico, there were relatively few English articles $(n=29)$ and they included nearly equal numbers of veal calf and cow-calf population types. In Canada, the majority of the studies $(n=130)$, occurred in Alberta $(n=60)$, Saskatchewan $(n=47)$, and Ontario $(n=23)$, where the majority of the country's feedlot and cow-calf operations are located (Statistics Canada, 2018). In the USA, the majority of the studies $(n=405)$, occurred in Texas $(n=50)$, Kansas $(n=45)$, Nebraska $(n=33)$, Oklahoma $(n=30)$, Florida $(n=27)$, and California $(n=23)$. In addition, in North America, 13 and $6 \%$ of the studies spanned multiple provinces or states in Canada and the USA, respectively. In Western Europe $(n=119)$, the two countries with the largest proportion of studies were Ireland $(n=27,23 \%)$ and Spain $(n=14,12 \%)$.

The number of articles published per year increased in an approximately linear trend over the decades since 1990. There were 6-18 articles per year from 1990 to 1999, 13-48 from 2000 to 2009 , and 41-55 from January 2010 to October 2016 (Fig. 2).

\section{Synthesis of results for challenge trials}

Challenge trials $(n=151)$ were used extensively for studies of vaccinations $(n=49)$, non-antibiotic feed additives $(n=43)$, and non-antibiotic medications $(n=19)$ (Fig. 3$)$. These trials described challenges with infectious agents or their toxins $(n=89)$ and immune stimulants $(n=52)$ administered to detect a measurable immune response in conjunction with another intervention. The infectious agents or toxins included Haemophilus somnus, Bovine herpes virus 1 (BoHV-1), Pasteurella spp., Mannheimia haemolytica, Bovine respiratory syncytial virus (BRSV), Bovine parainfluenza virus 3 (PI-3), Bovine rotavirus, Mycoplasma bovis, 
Fig. 1. Scoping review of non-antibiotic approaches for disease prevention and control in beef and veal production: PRISMA flow diagram of citations from literature search through to relevance screening and data extraction.
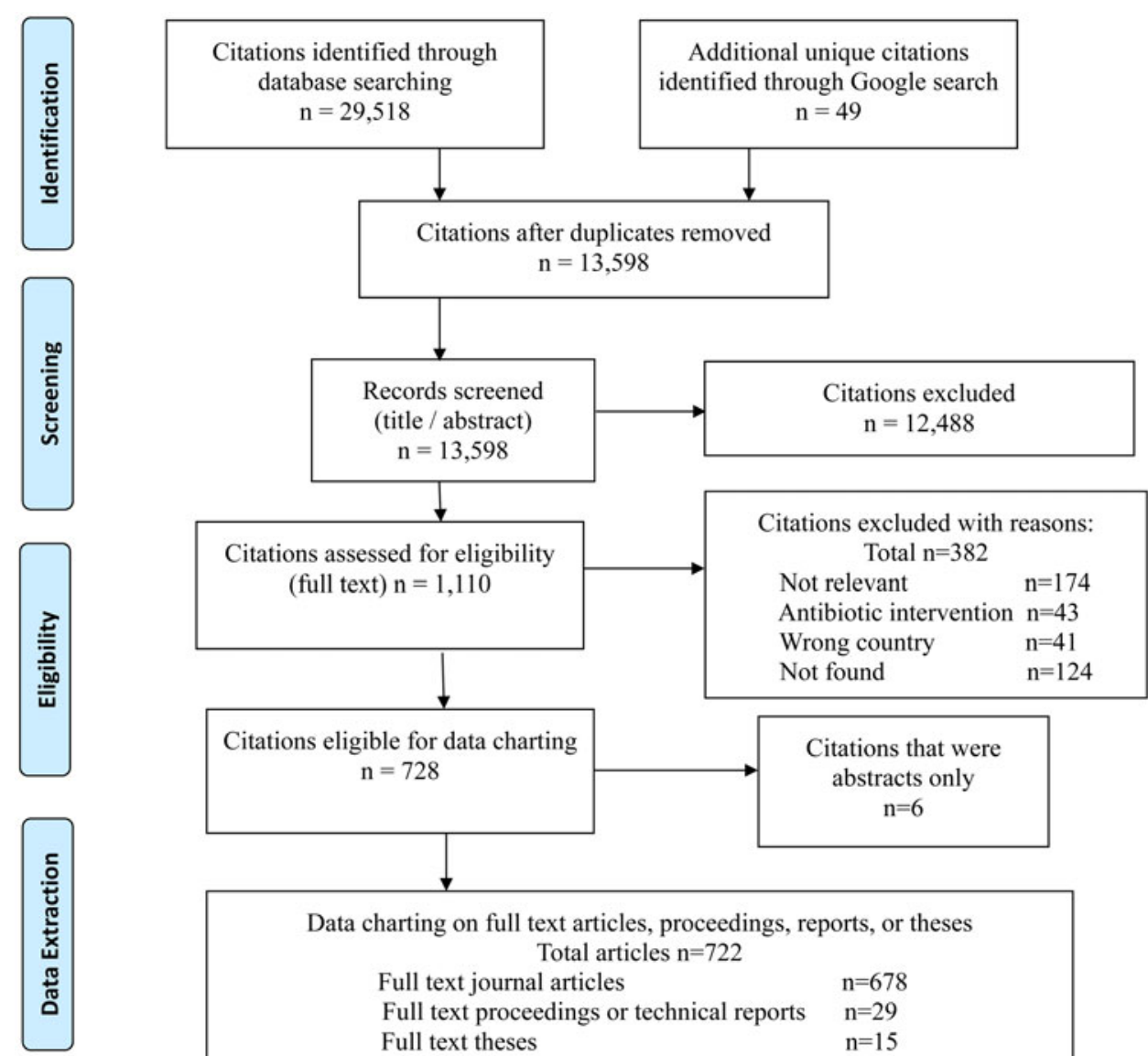

Citations that were abstracts only $\mathrm{n}=6$

Data charting on full text articles, proceedings, reports, or theses Total articles $\mathrm{n}=722$

Full text journal articles

$\mathrm{n}=29$

Full text theses $\quad n=15$

Salmonella spp., Salmonella toxins, Fusobacterium necrophorum, Bovine viral diarrhea virus (BVDV), Bovine leukemia virus, Mycobacterium bovis, Leptospira spp., Ureaplasma diversum, Mycobacterium avium (MAP), Brucella abortus, Histophilus somni, lipopolysaccharide, Escherichia coli strain K99+, and Fasciola hepatica. The immune stimulants included ovalbumin, porcine red blood cells (RBC), human RBC, keyhole limpet hemocyanin $(\mathrm{KLH})$, antigens (hen egg white lysozyme with DTH-inducing antigen Candida albicans), intradermal phytohemagglutinin (PHA). Other types of challenges $(n=10)$ included acidosis challenge, ACTH challenge, amphotericin-induced lameness, and induced wounds.

Outcomes most commonly reported in challenge trials included surrogate measures of disease and susceptibility $(n=112)$, morbidity $(n=91)$, respiratory disease $(n=48)$, and non-specific immunity $(n=47)$ (Fig. 4).

\section{Synthesis of results for clinical trials and observational studies}

\section{Non-antibiotic interventions}

The interventions evaluated in clinical trials and observational studies varied widely (Table 5). The most frequent interventions studied were feed additives, followed by breed type and then vaccines (Fig. 3). Clinical trials were the most frequent study design for the evaluation of feed additives, vaccinations, feed types, maternal antibody, medications, milk replacer additives, weaning, transportation, feeding regimes, and non-specific pre-conditioning. Observational studies were the most common study design for evaluation of breed type, biosecurity, environment, and housing. We charted data for 15 categories of non-antibiotic interventions, which are presented in decreasing order of frequency in Table 5. Details of the specific vaccine interventions studied in clinical trials are given in Supplementary Appendix 3, and details of the specific non-vaccine, non-antibiotic interventions studied in clinical trials are given in Supplementary Appendix 4.

\section{Comparison groups}

Among the 601 clinical trials and observational studies, the most commonly reported comparison group was a control group that received a different form or level of the intervention or exposure $(n=487)$. The next most commonly reported comparison group was the 'no treatment control or conventional practice' category $(n=235)$. A placebo or sham treatment group $(n=61)$ was utilized largely for vaccination trials $(n=39)$. Direct breed-to-breed comparisons for specific breeds were reported in 15 studies. Among the 167 clinical trials that investigated a non-antibiotic feed additive or medication, only 17 included an antibiotic comparison group (Supplementary Appendix 5). These 17 studies all evaluated the non-antibiotic approach for disease prevention or control, none for treatment in animals known to be clinically ill.

\section{Outcomes measured}

We extracted data for 18 categories of health outcomes. It was common for studies to report results for multiple outcomes. The 10 most frequently reported categories are presented in 
Table 4. Numbers of studies involving specific beef populations ${ }^{a}$ by country or region where challenge trials, clinical trials, and observational studies were conducted

\begin{tabular}{|c|c|c|c|c|c|c|c|}
\hline Specific population & $\begin{array}{l}\text { Canada } \\
(n=141)\end{array}$ & $\begin{array}{l}\text { USA } \\
(n=485)\end{array}$ & $\begin{array}{l}\text { Western Europe } \\
(n=124)\end{array}$ & $\begin{array}{l}\text { Australia or New } \\
\text { Zealand }(n=29)\end{array}$ & $\begin{array}{l}\text { South Americab or } \\
\text { Mexico }(n=29)\end{array}$ & $\begin{array}{l}\text { Eastern Europe or } \\
\text { Russia }(n=12)\end{array}$ & $\begin{array}{l}\text { Total } \\
(n=820)\end{array}$ \\
\hline Veal calves & 14 & 77 & 50 & 0 & 10 & 7 & 158 \\
\hline Beef cows/heifers & 5 & 14 & 7 & 3 & 4 & 1 & 34 \\
\hline Cow-calf & 21 & 74 & 13 & 6 & 9 & 1 & 124 \\
\hline Feedlot & 74 & 186 & 22 & 13 & 2 & 3 & 300 \\
\hline $\begin{array}{l}\text { Cattle (mixed or } \\
\text { unspecified populations) }\end{array}$ & 2 & 11 & 23 & 3 & 2 & 0 & 41 \\
\hline
\end{tabular}

${ }^{a}$ Some articles included more than one study and more than one specific population.

${ }^{\text {b}}$ South American countries included Brazil, Argentina, and Uruguay.

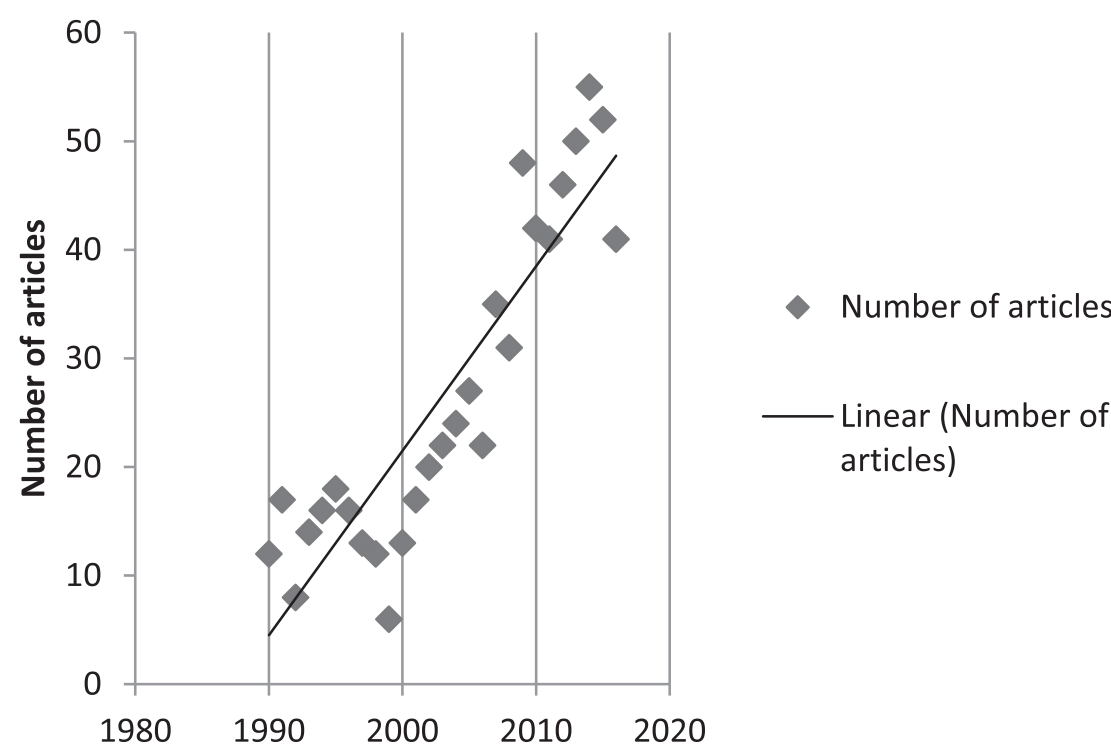

Fig. 2. Articles (full text journal articles, proceedings, reports, and theses) included in data charting published by year from January 1990 to October 2016.
Fig. 4. Surrogate measures of disease and susceptibility was the most commonly reported outcome category among clinical trials $(20 \%)$ whereas, surrogate measures of disease and susceptibility and mortality were equally the most commonly reported outcome categories among observational studies (29\% each) (Fig. 4). Details of the outcomes measured in the vaccine and non-vaccine clinical trials of non-antibiotic interventions are presented in Supplementary Appendices 3 and 4, respectively.

Among clinical trials and observational studies, the outcome 'treatments for illness' $(n=83)$ was most commonly reported in feedlot animals $(n=48)$ followed by veal calves $(n=22)$. The outcome diarrhea $(n=77)$ was more frequently reported in veal calves $(n=57)$ than other populations. Other clinical disease (i.e. non-respiratory and non-diarrheal infections) specifically identified by clinical disease $(n=23)$ such as infectious bovine keratitis, omphalitis, and otitis were reported in observational studies $(n=11)$ typically evaluating breed factors, and in clinical trials $(n=12)$ typically evaluating vaccines. Most studies reporting treatment cost $(n=26)$ were clinical trials $(n=23)$.

Of the 27 vaccine clinical trials conducted in feedlot cattle, there were eight that did not measure a clinically important outcome but did measure indices of immunity. These eight studies ranged in size from 8 to 179 individuals and were all conducted under experimental farm settings. Similarly, of the 11 vaccine clinical trials conducted in veal calves, there were three that did not measure a clinically important outcome. These three trials ranged in size from 10 to 200 calves with the largest being conducted on a commercial farm (Soehnlen et al., 2011).

\section{Study size}

Most studies reported the results and analyses at the individual level $(n=568)$ as opposed to the group $(n=28)$ or herd level $(n=66)$. Study sizes varied widely from 4 to $8,904,965$ animals. The size of clinical trials in experimental settings varied from 4 to 12,617 animals, whereas the size of clinical trials in commercial settings varied from 10 to 79,171 animals. The smallest studies ( $n=4-6$ animals) were typically clinical trials that evaluated feed type or a non-antibiotic feed additive in feedlot cattle housed under experimental settings with or without fistulae measuring acidosis, performance, digestion, and bio-mechanisms. The two largest studies $(n=2,542,266)$ and $(n=8,904,965)$ were observational studies of commercial cattle. The study with 2,542,266 animals evaluated the association of breed or genetics and the environment (i.e. season or year) on calf mortality and fertility 


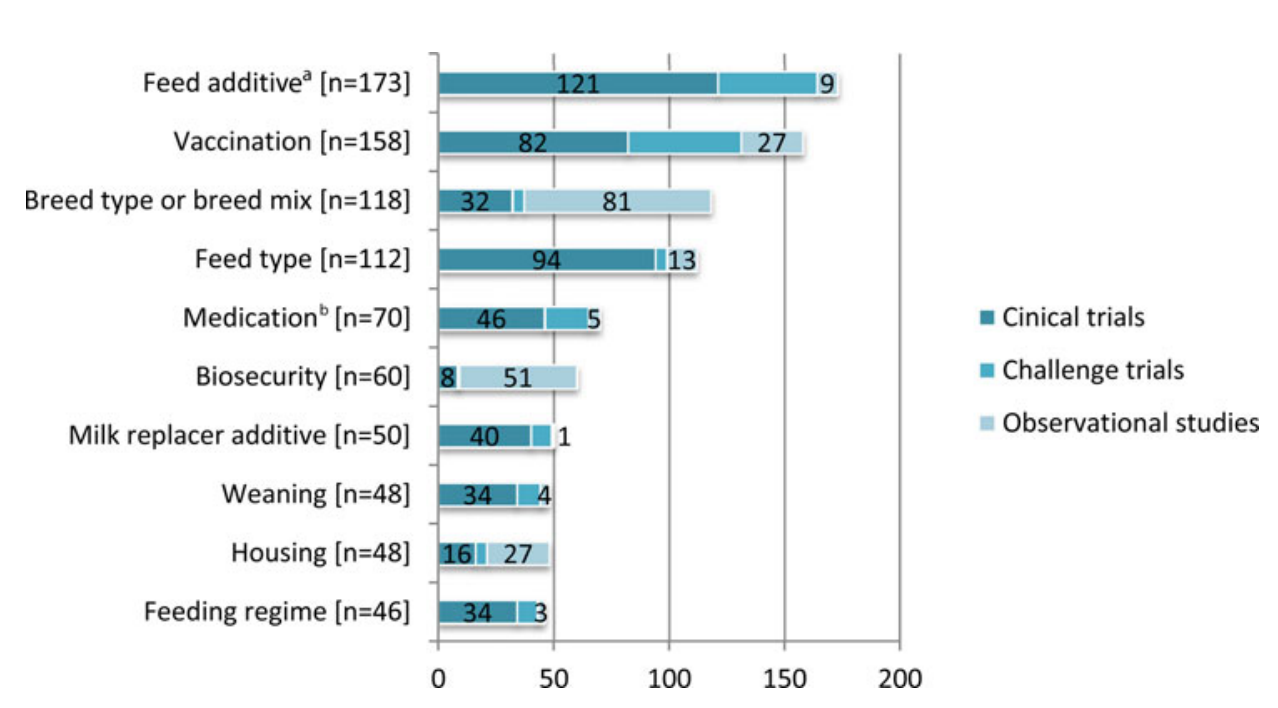

Fig. 3. The 10 most frequently reported nonantibiotic intervention categories in beef cattle and veal calves by study design. For purposes of this review, intervention also included both modifiable and non-modifiable risk factors. Some articles described more than one study design. Some studies reported multiple interventions.

${ }^{a}$ Feed additive included the addition of specific dietary components.

${ }^{\mathrm{b}}$ Medications included non-antibiotic medications or supplements administered directly to individual animals by injection, implant, or bolus.

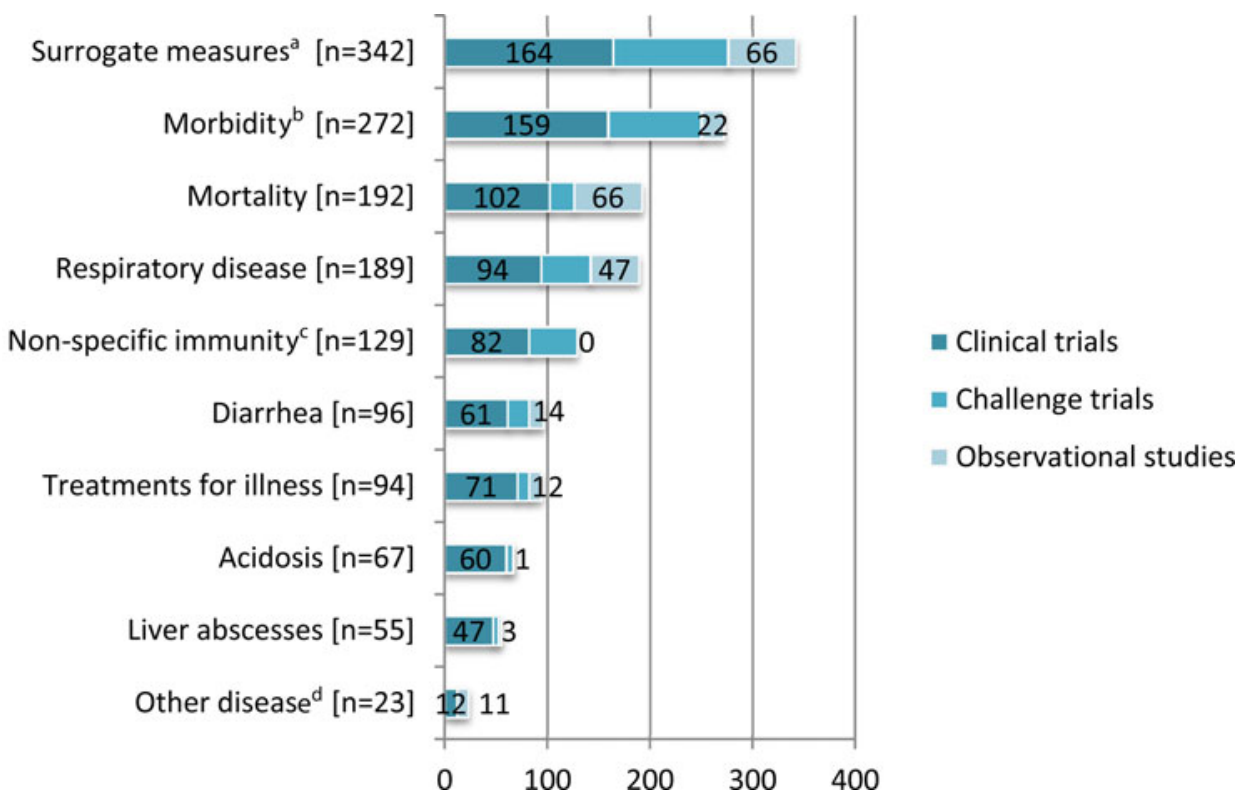

Fig. 4. The 10 most frequently reported outcomes of interest (Outcomes of interest included: surrogate measures of disease and susceptibility, indices of nonspecific immunity, non-specific morbidity, mortality, respiratory disease, diarrhea, treatments for illness, other infection (e.g. non-diarrheal, non-respiratory infections), pathology (e.g. post mortem findings), rumen or abomasum development, acidosis, liver abscesses, lameness or foot lesions total farm-level antibiotic use, injection site lesions, gene expression of immunity, abortion, and treatment cost.) in beef cattle and veal calf populations by study design (Some articles described more than one study design. Some studies reported multiple outcomes.).

${ }^{a}$ Surrogate measures of disease and disease susceptibility (i.e. infection with pathogen and biomarkers of specific immunity such as serology and cell mediated immunity).

${ }^{\mathrm{b}}$ Morbidity (i.e. non-specific illness or pyrexia).

${ }^{c}$ Non-specific immunity (i.e. immunoglobulins to non-infectious agents and immune biomarkers such as acute-phase proteins, and tumor necrosis factor).

${ }^{\mathrm{d}}$ Other disease (i.e. non-respiratory and non-diarrhea clinical infectious diseases).

of the British National herd (Gates, 2013), whereas the largest study evaluated the association between cohort level risk factors such as arrival month, sex, and cohort mean arrival weight on the mortality rate and culling risk in 16 US feedlots over multiple years (Babcock et al., 2013).

\section{Material for potential systematic review questions}

To meet our objective of assessing the feasibility of conducting systematic reviews, we explored the clinical trial data for all potential topic areas that shared some commonality of intervention, population, and a clinically important outcome. We found seven topic areas that may feasibly lead to systematic review questions assessing non-antibiotic interventions to reduce the need for medically important antibiotics in beef or veal production (Table 6 and Supplementary Appendix 6). Within these seven topic areas, there was some variation of specific interventions used and outcomes measured (Table 6). The full range of the specific interventions used within the identified topic areas are listed in Supplementary Appendix 6. Though we identified material for seven potential systematic review questions, only the material for BRD vaccines and feed type roughage for the prevention of liver abscesses in feedlot cattle included more than one study in commercial settings (Table 6). 
Table 5. Description of non-antibiotic interventions ${ }^{a}$ in beef or veal animals evaluated in clinical trials and observational studies from January 1990 to October 2016 presented in decreasing order of frequency

Non-antibiotic interventions that may reduce or prevent disease

Description of interventions or risk factors in clinical trials and observational studies

Feed additive including the addition of specific dietary components (non-antibiotic)

Total $(n=129)$

Clinical trial $(n=121,94 \%)$

Observational $(n=8,6 \%)$
Vitamins ( $A, E$, thiamine), cysteine-rich feather meal, trace minerals, maternal mineral supplementation, hormones, crude protein, fatty acids, organic acids, molasses, high fructose corn syrup, urea, rumen modifier, bicarbonate, anioncation buffer, wet brewer's grains, fibrolytic enzyme, wet brewer's or distillers' grains, ground flax, seaweed or plant extracts, essential oils, fish oil, yeast or yeast extracts, bicarbonate, probiotics, prebiotics, yeast fermentation extract, supplemental fat from safflower seed or cottonseed hulls, wheat straw versus beet pulp, anti-phospholipase antibody, polyclonal antibody, Actigen ${ }^{\circledR}$, ractopamine or zilpaterol

Breed

Total $(n=114)$

Clinical trial $(n=32,28 \%)$

Observational $(n=82,72 \%)$

Vaccinations (treatment group received vaccination, comparison group (s) received different vaccinations or vaccine protocol or no vaccination) Total $(n=108)$

Clinical trial $(n=82,76 \%)$

Observational $(n=26,24 \%)$

Breed or breed combination comparisons, heterosis versus purebred, sire and dam breed and heterosis, generations of rotational breeding, genome polymorphisms, BoLA type and sire effects, heritabilities of pre-weaning

Timing of vaccination, live versus inactivated vaccines, booster vaccination, various adjuvants, novel combinations of vaccines, methods and routes of administration, season of vaccination, efficacy of needle-free vaccination under cold and warm conditions.

Vaccine efficacy for specific infections including: BRD, IBVD, Moraxella bovis, S. association with disease, breed type as risk factor for diseases, single-nucleotide mortality, heritability for disease susceptibility, haplotypes, familial associations typhimurium, S. choleraesuis, S. Newport, S. dublin, Mycoplasma bovis, M. bovis cytotoxin, Rota viruses, corona virus, bovine herpes virus-1, Brucella bovis, Infectious bovine rhinotracheitis virus, parainfluenza-3 virus, bovine respiratory syncytial virus, Haemophilus somnus, Mannheimia haemolytica, Pasturella spp., E. coli, Clostridial spp., Leptospira spp., Fusobacterium necrophorum bacterin or leukotoxin, Arcanobacterium pyogenes polysin
Feed type

Total $(n=107)$

Clinical trial $(n=94,88 \%)$

Observational $(n=13,12 \%)$

Forage sources, chop length, silage, and forage level in diet, grain types, brewers or distillers grains as wet or dry, with or without solubles, corn gluten, by-product pellets, grain processing methods, feedlot diet, calf starter format, pasture mix, crude protein concentration, dietary starch and energy concentration, molasses, waste milk, alkaline hydrogen peroxide treated wheat straw, summer versus winter feeding strategies, self-selection of dietary ingredients versus total mixed ration

\section{Environment}

Total $(n=65)$

Clinical trial $(n=13,20 \%)$

Observational $(n=52,80 \%)$

Housed indoors versus outdoors in high ambient temperature, shade provided, rain shelters, extended summer and winter feeding strategies, efficacy of needle-free vaccination under cold and warm conditions, environmental conditions and spatial allowances during transportation, ambient temperature at birth, birthing seasons, vaccination season spring versus fall, exposure to sour gas sulfur dioxide, hydrogen sulfide, and volatile organic compounds (VOCs), high altitudes, geographic regions, climactic conditions upon feedlot entry

\author{
Biosecurity \\ Total $(n=56)$ \\ Clinical trial $(n=8,14 \%)$
}

Observational $(n=48,86 \%)$

Regrouping and relocation, multiple sources versus single source, source of calves, infection control, disinfection and housing types, presence of other animals on the farm (wildlife, game farms, poultry, sheep, goats, dogs), animal movements, production systems, feedlot management practices, sick calf management, calving management, replacement heifers born on farm versus purchased, community and rental pastures, bovine TB management, badger activity, paraTB previously diagnosed on farm, movement of pregnant cows with persistently infected BVD calves, Johnes test and control practices, application of producer knowledge regarding biosecurity

\section{Maternal antibody}

Total $(n=52)$

Clinical trial $(n=41,79 \%)$

Observational $(n=11,21 \%)$

Non-antibiotic medication or supplement administered directly by

injection, implant, or bolus

Total $(n=51)$

Clinical trial $(n=46,90 \%)$

Observational $(n=5,10 \%)$

Housing

Total $(n=42)$

Clinical trial $(n=16,38 \%)$

Observational $(n=26,62 \%)$
Access to and quality of maternal IgG colostrum antibody. In some studies it was measured to indicate immune response to another intervention such as a feed additive

Trace minerals, yeast, hormones, recombinant bST, growth implant, beta-adrenergic agonists, non-steroidal anti-inflammatory drugs (NSAIDs), vitamins $B, A, D, E$, and $C$, zinc, selenium yeast, parapox ovis-based immunomodulator, insulin, botanical extracts, DNA immunostimulant (Zelnate), mycobacterium cell wall fraction (Immunoboost ${ }^{\circledR}$ ), nitric oxide, brown seaweed extract, probiotic, homeopathic treatment, Convert calf gel ${ }^{\circledR}$ mix, Tween $80^{\circledR}$, non-pathogenic $E$. coli strain Nissle 1917

Single versus group pen, grouping by age, animal pen density, presence of a sick bay, tie stall versus free stall, calving facilities and protocols, winter housing, post weaning housing, bunk manger space and management, flooring and bedding, days on pasture 
Table 5. (Continued.)

\begin{tabular}{|c|c|}
\hline Non-antibiotic interventions that may reduce or prevent disease & $\begin{array}{l}\text { Description of interventions or risk factors in clinical trials and observational } \\
\text { studies }\end{array}$ \\
\hline $\begin{array}{l}\text { Milk or colostrum replacer additive } \\
\text { Total }(n=41) \\
\text { Clinical trial }(n=40,98 \%) \\
\text { Observational }(n=1,2 \%)\end{array}$ & $\begin{array}{l}\text { Prebiotic, probiotic, synbiotic, whey protein, Vit A and E levels, lactoferrin, trace } \\
\text { minerals (source and type), chromium, selenium, yeast or yeast extract, } \\
\text { fermentation product, fatty acids, clinoptilolite (zeolite), milk-free versus } \\
\text { milk-based, commercial lacteal-derived colostrum replacer, spray-dried animal } \\
\text { plasma, clenbuterol, plane of nutrition, roughage supplement, essential oils }\end{array}$ \\
\hline $\begin{array}{l}\text { Weaning } \\
\text { Total }(n=38) \\
\text { Clinical trial }(n=34,89 \%) \\
\text { Observational }(n=4,11 \%)\end{array}$ & $\begin{array}{l}\text { Weaning protocols (e.g. 2-stage weaning with nose flaps, levels of contact with } \\
\text { dam, yard weaning with or without feed-bunk training, weaned with or without } \\
\text { trainer cow, early versus late weaning, organic versus conventional versus } \\
\text { intensive beef system), concentrate dependent weaning, milk versus concentrate, } \\
\text { creep feeding, time from weaning to shipping, dam age, weaned and housed } \\
\text { versus returned to pasture, weaned concurrently or consecutively with } \\
\text { castration, length of weaning period and timing of vaccination before weaning or } \\
\text { on arrival at feedlot, regular weaning protocol versus Michigan State University } \\
\text { protocol }\end{array}$ \\
\hline $\begin{array}{l}\text { Feeding regime } \\
\text { Total }(n=37) \\
\text { Clinical trial }(n=34,92 \%) \\
\text { Observational }(n=3,8 \%)\end{array}$ & $\begin{array}{l}\text { Feed, energy, protein, or nutrient restriction, beef cow grain supplementation } \\
\text { schedule, ad libitum versus limit fed, rangeland protocols for supplementary } \\
\text { forage and other nutrients, grain adaption protocol, amount of roughage fed, } \\
\text { milk replacer delivery system or allowances, starter diet/creep feeding protocols } \\
\text { at weaning, feed amounts at various periods of gestation and lactation, } \\
\text { self-selection of dietary ingredients versus total mixed ration }\end{array}$ \\
\hline $\begin{array}{l}\text { Transportation } \\
\text { Total }(n=23) \\
\text { Clinical trial }(n=17,74 \%) \\
\text { Observational }(n=6,26 \%)\end{array}$ & $\begin{array}{l}\text { Truck stocking density, distance traveled, transportation versus none, } \\
\text { transportation and co-mingling }\end{array}$ \\
\hline $\begin{array}{l}\text { Maternal vaccination } \\
\text { Total }(n=16) \\
\text { Clinical trial }(n=11,69 \%) \\
\text { Observational }(n=5,31 \%)\end{array}$ & Vaccine timing, evaluation of specific disease agent vaccines \\
\hline $\begin{array}{l}\text { Pre-conditioning (general or unspecified) } \\
\text { Total }(n=11) \\
\text { Clinical trial }(n=8,73 \%) \\
\text { Observational }(n=3,27 \%)\end{array}$ & $\begin{array}{l}\text { Certified preconditioning program versus Kentucky Gold Tag program, } \\
\text { vaccinated or conditioned calves sold through special auction types, timing of } \\
\text { vaccination before or after shipment, number of vaccines prior to shipment, } \\
\text { preconditioning program type, preconditioning nutrition, branding method, } \\
\text { preconditioning and length of transportation }\end{array}$ \\
\hline
\end{tabular}

Total number of clinical trials and observational studies described $(n=890)$.

Study designs: clinical trials $(n=583,66 \%)$ and observational studies $(n=293,33 \%)$.

${ }^{a}$ Some articles describing non-antibiotic interventions reported multiple studies and some studies reported multiple interventions.

\section{Discussion}

This scoping review of the research evaluating non-antibiotic approaches that may reduce the need to use medically important antibiotics in beef and veal production relevant in the North American context identified a large body of diverse literature. The diversity of this research pertained not only to the specific interventions and specific populations studied but also to the comparison groups and outcomes measured. Though there was a large volume of research evaluating a considerable variety of interventions, there was relatively little replication of studies. Our findings that this body of literature had breadth but limited depth reflected those of Murphy et al. (2016) as reported in their scoping review of non-antibiotic factors or interventions to reduce AMR in North American cattle. Because the findings of a single trial can be the result of a random event, clinical and policy decisions are best guided by the findings among multiple relevant studies (Garg et al., 2008). Clinicians and policy decision makers can benefit from a credible summary of the primary research for a particular topic, particularly in the form of a systematic review (Garg et al., 2008). However, replication of research is a prerequisite for combining and summarizing the research on a specific topic.

We charted data regarding the farm settings of the animals in the study in terms of experimental versus commercial farms. The majority of clinical trials occurred on experimental farms. Some experimental farms are as large as some commercial farms, and so may closely mimic commercial settings. However, it is unknown to what extent the experimental versus commercial farm settings impact external validity in beef cattle and veal calf research.

We chose to focus our reporting on clinical trials rather than challenge trials as challenge trials have a tendency to report more favorable outcomes compared to clinical trials of the same intervention (Wisener et al., 2014; Theurer et al., 2015). Nevertheless, challenge trials serve an important purpose in the research continuum, providing proof of concept prior to field trials under natural exposure conditions (Sargeant et al., 2014).

Consistent with Ribble et al. (2010) we found that there was a dearth of clinical trials evaluating feedlot management interventions such as biosecurity, infection control, animal mixing and animal movement, and pen densities. These types of interventions may be difficult to study under clinical trial conditions; moreover, it may be difficult to source funding for trials of non-antibiotic management interventions (Ribble et al., 2010). These types of interventions were more frequently studied though observational approaches, which can provide a high level of evidentiary value about an intervention and can be used in systematic reviews (O'Connor and Sargeant, 2014). However, even among the 
Table 6. Articles describing similar specific non-antibiotic interventions, specific populations, and clinically important outcomes ${ }^{\mathrm{a}}$ in beef or veal animals evaluated from among the clinical trials $(n=439)$ from January 1990 to October 2016 that may feasibly support systematic reviews

\begin{tabular}{|c|c|c|c|}
\hline Intervention & Intervention specifics & Population & $\begin{array}{l}\text { Clinically important health } \\
\text { outcomes }\end{array}$ \\
\hline $\begin{array}{l}\text { Vaccinations (BRD) } \\
(n=24)\end{array}$ & $\begin{array}{l}\text { Vaccine types }(n=12) \\
\text { Vaccination-revaccination and vaccination schedules }(n=10) \\
\text { Novel vaccine routes and novel combinations of viral-bacterial } \\
\text { respiratory vaccines }(n=1) \\
\text { Vaccination site on animal }(n=1)\end{array}$ & $\begin{array}{l}\text { Feedlot cattle } \\
\text { Exp. }^{\mathrm{b}}(n=15) \\
\text { Comm. }^{\mathrm{c}}(n=8) \\
\text { Unclear }(n=1)^{\text {Unde }}\end{array}$ & $\begin{array}{l}\text { Respiratory disease }(n=16) \\
\text { Morbidity }{ }^{\mathrm{d}}(n=22) \\
\text { Mortality }(n=15) \\
\text { Treatments for illness } \\
(n=10)\end{array}$ \\
\hline $\begin{array}{l}\text { Feed additive } \\
\text { (probiotics) } \\
(n=5)\end{array}$ & $\begin{array}{l}\text { Yeast culture live }(n=2) \text {, yeast (live or cell wall extract) }(n=1) \text {, DFM } \\
\left.\text { product (Bovamine Defend }{ }^{\circledR}\right)(n=1) \text {, commercial feed additives } \\
\text { containing probiotics and/or feed enzymes) }(n=1)\end{array}$ & $\begin{array}{l}\text { Feedlot cattle } \\
\text { Exp. }(n=5) \\
\text { Comm. }(n=0)\end{array}$ & $\begin{array}{l}\text { Respiratory disease }(n=3) \\
\text { Morbidity }(n=5) \\
\text { Mortality }(n=4) \\
\text { Treatments for illness }(n=3)\end{array}$ \\
\hline $\begin{array}{l}\text { Feed additive } \\
\text { supplement } \\
\text { (daily vitamin E) } \\
(n=5)\end{array}$ & $\begin{array}{l}\text { Vit. E levels }(n=1) \text {, Vit E } 550 \text { IU or cysteine-rich feather meal }(n=1) \text {, Vit E } \\
2000 \text { IU }(n=1) \text {, Vitamin E with either flaxseed oil or safflower oil or alone } \\
(n=1) \text {, Vit E (2000 IU) supplement for various lengths of time }(n=1)\end{array}$ & $\begin{array}{l}\text { Feedlot cattle } \\
\text { Exp. }(n=4) \\
\text { Comm. }(n=1)\end{array}$ & $\begin{array}{l}\text { Respiratory disease }(n=1) \\
\text { Morbidity }(n=4) \\
\text { Mortality }(n=2) \\
\text { Treatments for illness }(n=3)\end{array}$ \\
\hline $\begin{array}{l}\text { Feed additive } \\
\text { (chromium } \\
\text { supplement) } \\
(n=6)\end{array}$ & $\begin{array}{l}\text { Organic versus inorganic chromium }(n=3) \text {, chelated chromium }(n=2) \text {, } \\
\text { unspecified chromium }(n=1)\end{array}$ & $\begin{array}{l}\text { Feedlot cattle } \\
\text { Exp. }(n=6) \\
\text { Comm. }(n=0)\end{array}$ & $\begin{array}{l}\text { Respiratory disease }(n=1) \\
\text { Morbidity }(n=6) \\
\text { Mortality }(n=1) \\
\text { Treatments for illness }(n=1)\end{array}$ \\
\hline $\begin{array}{l}\text { Medications } \\
\text { NSAID }^{f} \\
(n=5)\end{array}$ & $\begin{array}{l}\text { Flunixin meglumine as ancillary treatment for BRD }(n=2) \text {, flunixin, } \\
\text { ketoprofen and carprofen tested as ancillary treatment for respiratory } \\
\text { disease }(n=1) \text {, meloxicam at castration }(n=2)\end{array}$ & $\begin{array}{l}\text { Feedlot cattle } \\
\text { Exp. }(n=3) \\
\text { Comm. }(n=1) \\
\text { Unclear }(n=1)\end{array}$ & $\begin{array}{l}\text { Respiratory disease }(n=4) \\
\text { Morbidity }(n=5) \\
\text { Mortality }(n=2) \\
\text { Treatments for illness }(n=2)\end{array}$ \\
\hline $\begin{array}{l}\text { Feed type } \\
\text { (roughage and grains) } \\
(n=41)\end{array}$ & $\begin{array}{l}\text { Roughage type, processing methods, and roughage levels }(n=14) \text {, forage } \\
\text { feeding protocols }(n=3) \text {, grain feeding protocols }(n=3) \text {, grain processing } \\
\text { methods }(n=9) \text {, grain type }(n=6) \text {, replacing barley grain }(n=6)\end{array}$ & $\begin{array}{l}\text { Feedlot cattle } \\
\text { Exp. }(n=36) \\
\text { Comm. }(n=5) \\
\text { Unclear }(n=1)\end{array}$ & $\begin{array}{l}\text { Liver abscesses }(n=26) \\
\text { Acidosis }(n=21)\end{array}$ \\
\hline $\begin{array}{l}\text { Milk replacer additive } \\
\text { (probiotics) } \\
(n=14)\end{array}$ & $\begin{array}{l}\text { Probiotics including yeasts }(n=6) \text {, prebiotics }(n=4) \text {, combination } \\
\text { probiotic and/or prebiotic }(n=4)\end{array}$ & $\begin{array}{l}\text { Veal calves } \\
\text { Exp. }(n=14) \\
\text { Comm. }(n=0)\end{array}$ & $\begin{array}{l}\text { Diarrhea }(n=14) \\
\text { Mortality }(n=2) \\
\text { Morbidity }(n=5)\end{array}$ \\
\hline
\end{tabular}

${ }^{a}$ Clinically important health outcomes (i.e. mortality, non-specific morbidity, respiratory disease, treatments for illness, liver abscesses, and acidosis).

${ }^{b}$ Exp. (i.e. populations living under experimental settings).

'Comm. (i.e. populations living under commercial settings).

${ }^{d}$ Morbidity (i.e. non-specific illness or pyrexia).

${ }^{\mathrm{e}}$ Treatments for illness (i.e. sequential antibiotic treatments administered to sick animals)

${ }^{f}$ NSAID (nonsteroidal anti-inflammatory medication).

observational study designs that can be used for hypothesis testing, the inherent selection and confounding biases that can result from the lack of randomization must be carefully considered in the decision to base a systematic review on these studies (O’Connor and Sargeant, 2014).

Had we focused exclusively on studies that compared a specific alternative intervention group to a preventive antibiotic group, our scoping review would have been very limited: first, because the studies in which a specific non-antibiotic alternative intervention group was compared to an antibiotic treatment group were limited to feed additive and medication interventions; and second, because there were relatively few feed additive or medication intervention studies with a preventive antibiotic comparison group. In the literature that described non-antibiotic approaches to improve the health of beef or veal animals and thereby reduce the need for antibiotics, this lack of direct comparison to a preventive antibiotic comparison group may represent a knowledge gap for decision-making regarding non-antibiotic alternatives.

The comparison group(s) did not always include a 'no treatment or conventional practice' control group, but more commonly consisted of animals receiving different levels of the same treatment or a variation of the treatment. In some cases, including a no treatment control group would have resulted in an unacceptable standard of care for that group. For many studies, we found it difficult to determine what may have been considered the 'no treatment or conventional practice' control in the context of the study, and thus we may have misclassified these comparison groups. For example, one study evaluated the effect of late gestation drylot rations with two levels of protein degradability and fat content on subsequent calf feedlot morbidity and mortality without stipulating which level of protein degradability and fat content was the conventional practice for these diets (Wilson et al., 2015).

We found that, among the vaccine clinical trials under natural exposure conditions, there were some that did not report a clinically important outcome but rather reported indices of specific or non-specific immunity and other outcomes. This may represent a missed opportunity in vaccine clinical trial research, particularly for natural exposure studies for which a clinically important outcome could have been measured. Systematic reviews that do not include a clinically important outcome but rather only include indirect outcomes, such as indices of immunity, can be subject to downgrading the quality of evidence available to answer a specific review question in a Grades of Recommendation, Assessment, Development and Evaluation (GRADE) analysis (Ryan et al., 2016). The GRADE approach to evaluating the quality of evidence incorporates an explicit evaluation of the importance of the outcomes measured, such that indirect outcomes provide a relatively 
lower quality of evidence than patient-important or animalimportant outcomes, as determined by guidelines or the clinician, researcher, or patient perspectives (Guyatt et al., 2011a, 2011b). In the human medical literature, the assumption that the intervention effect on a biomarker reflects the intervention effect on a patientimportant outcome can be false (Fleming and Powers, 2012). However, indices can serve as useful outcomes to provide insights for 'proof of concept' trials (Fleming and Powers, 2012).

This scoping review described the literature on the broad topic of non-antibiotic interventions without attempting to demonstrate if these interventions could actually reduce the need for antibiotics. Summarizing the efficacy of various interventions and assessing the methodological quality or risk of bias of the included articles was beyond the scope of this review. However, in addition to mapping the broader intervention literature, we attempted to identify areas where the available literature may support systematic reviews that could summarize the effect of particular non-antibiotic approaches within the broader topic area. Systematic reviews of interventions combine similar studies together to summarize the overall effectiveness of particular interventions. The purpose of the systematic review determines the scope of the review question as broad versus narrow (Higgins and Green, 2011). The scope then informs the degree of similarity among each of the study PICO components: specific population, intervention, comparison group, and outcome measured. We found relatively few similar studies for any specific intervention. Theurer et al. (2015) also reported finding limited published evidence to support a systematic review and meta-analysis of the effectiveness of commercially available vaccines against BRDs, a topic area of great importance for the reduction in the use of medically important antibiotics in the beef industry (Cameron and McAllister, 2016). Ribble et al. (2010) reported finding few nonvaccine intervention studies published in the last 20 years that did not involve the use of antibiotics in their review of alternative practices to antimicrobial use for disease control in commercial feedlots. Among the studies we identified with similar specific interventions we found a considerable range of outcomes reported. In systematic reviews, studies with disparate outcomes may not be meaningfully synthesized (i.e. combined). A lack of commonality in measured outcomes can result in some studies being excluded from a systematic review, resulting in an overall loss of research information needed to answer specific research questions about a summary effect size or to understand factors that affect that effect size. The outcome(s) selected for a systematic review of an intervention should be important to the end-user (O'Connor et al., 2014). Despite the availability of multiple studies evaluating a specific intervention in a specific population, a lack of a common outcome restricts the number of studies that can contribute to the systematic review.

We used an arbitrary minimum of five clinical trials with some commonality of the intervention, population, and measured outcomes to identify potentially feasible topics for a systematic review and meta-analysis. Technically, a minimum of two studies is sufficient to conduct a meta-analysis if those studies are similar enough to combine in a meaningful way (Borenstein et al., 2009). However, an insufficient number of studies limits the opportunity to assess between-study variability, which in turn impacts the interpretation and meaning of the meta-analysis (Borenstein et al., 2009). Depending on the systematic review question, there may be good reasons to combine studies that are somewhat dissimilar - for example, to explore the reasons for different results among the studies (Ioannidis et al., 2008).
In this scoping review, we identified seven topic areas for which it may be feasible to conduct a systematic review to answer a specific question about a specific intervention in a specific population measuring a specific outcome. The topic area with the most clinical trials was vaccines for BRD. Theurer et al. (2015) reported a systematic review and two meta-analyses for commercial BRD viral antigen vaccines in beef calves and in dairy calves in which two trials in beef calves and three trials in dairy calves with unspecified sex were included. We found more trials than Theurer et al. (2015) but we did not restrict BRD vaccines to commercially available vaccines. Larson and Step (2012) reported a meta-analysis for commercial BRD bacterial antigen vaccine effectiveness in feedlot cattle that included six clinical trials published since 1990. Though some knowledge synthesis has been conducted on the topic of commercial BRD vaccines, updated systematic reviews into commercial BRD vaccines could explore factors that impact the summary effect of different vaccines.

Within the identified seven topic areas, we observed some variation in the specifics of the interventions and the outcomes measured. Future primary research could focus on these seven specific topic areas with an emphasis on building a body of research on specific interventions with more depth. These primary studies could be further assessed using systematic review and meta-analysis methods to answer specific questions about the overall effectiveness of that intervention and to explore sources of variation among the studies.

This scoping review had several potential limitations. First, we included a wide variety of interventions in our search terms, but may have failed to include all possible search terms for specific interventions, thereby potentially missing articles. Systematic reviews of specific interventions should include a more comprehensive search. Second, we may have overlooked some nonantibiotic interventions or health outcomes if they were not listed in the article title or abstract. Third, we accessed only publically available sources through data platforms available via the University of Guelph, and so we may have missed additional articles such as unpublished studies generated by companies testing products. We attempted to overcome this potential deficit using a Google search, but we recognize that any Google search is neither repeatable nor transparent. Google is a search engine and not a data platform, and so Google was unable to deliver meaningful results for our extensive number of search terms in a Boolean string (Grindlay et al., 2012). Nevertheless, we obtained the majority of the theses, for which there were no subsequent published articles, through the Google search. Fourth, we were unable to search the CAB Direct platform due to technical difficulties and without the addition of studies identified through that platform we may not have achieved as comprehensive a search as intended. Grindlay et al. (2012) compared the coverage of veterinary journals by nine databases and found that $\mathrm{CAB}$ Abstracts had excellent coverage, and so it is possible that the $\mathrm{CAB}$ platform contained relevant articles that our search did not identify. Fifth, our data charting process would have been more accurate had we charted the data at the individual study level rather than at the article level. However, with only $9 \%$ of our relevant articles describing more than one study we do not think that charting the data at the article level substantially impacted our findings. Finally, we did not chart data regarding inherent bias in the included studies such as randomization of clinical trials, lack of concealment or blinding, loss to follow-up, or selective outcome reporting. Any systematic review utilizing the results of 
this scoping review should include a risk of bias assessment (Higgins and Green, 2011).

\section{Conclusion}

In this scoping review, we described the literature on nonantibiotic approaches for disease prevention and control in beef and veal production. Although there was considerable volume and breadth of research within this body of literature, there was limited depth. The research diversity pertained not only to specific interventions and populations but also to the comparison groups and outcomes measured. Despite a large volume of research evaluating a huge variety of interventions there was relatively little replication of studies. There were relatively few clinical trials utilizing a preventive antibiotic comparison group. No studies evaluated a non-antibiotic treatment compared to an antibiotic treatment in ill animals. Some clinical trials did not report clinically important outcomes.

Systematic reviews and meta-analyses, if not already done, could be conducted for the seven topic areas identified as having sufficient literature with enough commonality to combine. These could potentially answer questions about the summary effectiveness of specific interventions and explore sources of variation among studies (i.e. what factors influence different results found among similar studies). Future primary research could focus on these seven topic areas, with the inclusion of clinically important outcomes, thereby enhancing the depth of this research and provide opportunities for exploration of variation among similar studies. Future primary research could also include preventive antibiotic use comparison groups where appropriate to enhance the evidence for antibiotic alternatives in beef and veal production.

Supplementary material. The supplementary material for this article can be found at https://doi.org/10.1017/S1466252319000252.

Acknowledgements. We thank our stakeholders for their invaluable guidance. We also would thank our science librarian, Ms. Ali Versluis, for her help.

Author contributions. LW coordinated the project, acted as the primary reviewer for relevance screening and data charting, analyzed data, interpreted the results, and wrote the manuscript drafts. JS oversaw the work, piloted the relevance screening and data charting forms, assisted with the interpretation of results, reviewed manuscript drafts, and approved the final manuscript. AOC provided guidance for the interpretation of the results, commented on the manuscript drafts, and approved the final manuscript. TOS provided guidance for the interpretation of the results, commented on the manuscript drafts, and approved the final manuscript. SM provided guidance for the interpretation of the results, commented on the manuscript drafts, and approved the final manuscript. AN conducted relevance screening and data charting as a second reviewers, commented on manuscript drafts, and approved the final manuscript version. TR conducted relevance screening and data charting as a second reviewer, commented on manuscript drafts, and approved the final manuscript version.

Financial support. Funding support for this scoping review was provided by the Ontario Ministry of Agriculture, Food and Rural Affairs, and through an Ontario Veterinary College PhD Fellowship.

Conflict of interest. None of the authors have conflicts to declare.

\section{References}

Amachawadi RG and Nagaraja TG (2016) Liver abscesses in cattle: a review of incidence in Holsteins and of bacteriology and vaccine approaches to control in feedlot cattle. Journal of Animal Science 94, 1620-1632.
American Veterinary Medical Association (2019) Definitions for disease prevention, control and treatment [Online]. Available at https://www.avma.org/ KB/Policies/Pages/AVMA-Definitions-of-Antimicrobial-Use-for-TreatmentControl-and-Prevention.aspx (Accessed 8 November 2019).

Arksey H and O'Malley L (2005) Scoping studies: towards a methodological framework. International Journal of Social Research Methodology 8, 19-32.

Babcock AH, Cernicchiaro N, White BJ, Dubnicka SR, Thomson DU, Ives SE, Scott HM, Milliken GA and Renter DG (2013) A multivariable assessment quantifying effects of cohort-level factors associated with combined mortality and culling risk in cohorts of U. S. commercial feedlot cattle. Preventive Veterinary Medicine 108, 38-46.

Borenstein M, Hedges LV, Higgins JPT and Rothstein HR (2009) Introduction to Meta-Analysis. West Sussex, UK: John Wiley \& Sons Ltd, pp. 363-364.

Cameron A and McAllister TA (2016) Antimicrobial usage and resistance in beef production. Journal of Animal Science and Biotechnology 7, 1-22.

CDDEP (Centre for Disease Dynamics, Economics and Policy) (2015) State of the World's Antibiotics 2015. Washington, DC: CDDEP, p. 38.

FAO (Food and Agriculture Organization of the United Nations) (2016) The FAO action plan on antimicrobial resistance 2016-2020, pp. 1-12 [Online]. Available at http://www.fao.org/publications or http://www.fao. org/3/a-i5996e.pdf (Accessed 6 July 2018).

Fleming TR and Powers JH (2012) Biomarkers and surrogate endpoints in clinical trials. Statistics in Medicine 31, 2973-2984.

Garg AX, Hackam D and Tonelli M (2008) Systematic review and meta-analysis: when one study is just not enough. Clinical Journal of the American Society of Nephrology 3(Special Feature: Methods Series), 253-260.

Gates MC (2013) Evaluating the reproductive performance of British beef and dairy herds using national cattle movement records. Veterinary Record, 1-14. doi: $10.1136 / v r .101488$.

Government of Canada (2018) Responsible use of medically important antimicrobials in animals [Online]. Available at https:/www.canada.ca/en/ public-health/services/antibiotic-antimicrobial-resistance/animals/actions/ responsible-use-antimicrobials.html (Accessed 7 March 2019).

Grindlay DJC, Brennan ML and Dean RS (2012) Searching the veterinary literature: a comparison of the coverage of veterinary journals by nine bibliographic databases. Journal of Veterinary Medical Education 39, 404-412.

Guyatt GH, Oxman AD, Kunz R, Atkins D, Brozek J, Vist G, Alderson P, Glasziou P, Falck-Ytter $Y$ and Schünemann HJ (2011a) GRADE Guidelines: 2. Framing the question and deciding on important outcomes. Journal of Clinical Epidemiology 64, 395-400.

Guyatt GH, Oxman AD, Kunz R, Woodcock J, Brozek J, Helfand M, Alonso-Coello P, Falck-Ytter Y, Jaeschke R, Vist G, Akl EA, Post PN, Norris S, Meerpohl J, Shukla VK, Nasser $M$ and Schünemann HJ (2011b) GRADE Guidelines: 8. Rating the quality of evidence - indirectness. Journal of Clinical Epidemiology 64, 1303-1310.

Hässig M and Kretschmar S (2016) Evidence-based use of antibiotics in veal calves with diarrhea. Open Journal of Veterinary Medicine 6, 28-39.

Hernández J, Benedito JL, Abuelo A and Castillo C (2014) Ruminal acidosis in feedlot: from aetiology to prevention. The Scientific World Journal 2014, 702572.

Higgins JPT and Green S (eds) (2011) Cochrane Handbook for Systematic Reviews of Interventions. Version 5.1.0 (updated March 2011). The Cochrane Collaboration [Online]. Available at http://www.handbook.cochrane.org.

Hodgins DC, Conlon JA and Shewen PE (2002). Respiratory viruses and bacterial in cattle. In Brogden KA and Guthmiller JM (eds), Polymicrobial Diseases, 1st Edn. Washington, DC: ASM Press, Chapter 12. Available at https://www.ncbi.nlm.nih.gov/books/NBK2480/

Hussein HS and Berger LL (1995) Effects of feed intake and dietary level of wet corn gluten feed on feedlot performance, digestibility of nutrients, and carcass characteristics of growing-finishing beef heifers. Journal of Animal Science 73, 3246-3252.

Ioannidis J, Patsopoulos N and Rothstein H (2008) Reasons or excuses for avoiding meta-analysis in forest plots. Research Methodology 336, 1413-1415.

Larson RL and Step DL (2012) Evidence-based effectiveness of vaccination against Mannheimia haemolytica, Pasteurella multocida, and Histophilus somni in feedlot cattle for mitigating the incidence and effect of bovine 
respiratory disease complex. Veterinary Clinics: Food Animal Practice 28, 97-106.

Laxminarayan R, Duse A, Wattal C, Zaidi AKM, Wertheim HFL, Sumpradit N, Vlieghe E, Hara GL, Gould IM, Goossens H, Greko C, So AD, Bigdeli M, Tomson G, Woodhouse W, Ombaka E, Peralta AQ, Qamar FN, Mir F, Kariuki S, Bhutta ZA, Coates A, Bergstrom R, Wright GD, Brown ED and Cars O (2014) Antibiotic resistance - the need for global solutions. Lancet Infectious Disease Commission 13, 1057-1098.

Levac D, Colquhoun H and O'Brien KK (2010) Scoping studies: advancing the methodology. Implementation Science 5, 1-9.

Murphy CP, Fajt VR, Scott HM, Foster MJ, Wickwire P and McEwen SA (2016) Scoping review to identify potential non-antimicrobial interventions to mitigate antimicrobial resistance in commensal enteric bacteria in North American cattle production systems. Epidemiology and Infection 144, 1-18.

Nagaraja TG and Lechtenberg KF (2007) Liver abscesses in feedlot cattle. Veterinary Clinics: Food Animal Practice 23, 351-369.

O'Connor AM and Sargeant JM (2014) Meta-analyses including data from observational studies. Preventive Veterinary Medicine 113, 313-322.

O'Connor AM, Anderson KM, Goodell CK and Sargeant JM (2014) Conducting systematic reviews of intervention questions 1: writing the review protocol, formulating the question and searching the literature. Zoonoses and Public Health 61(Suppl. 1), 28-38.

OIE (World Organization for Animal Health) (2015) List of antimicrobial agents of veterinary importance, pp. 1-9 [Online]. Available at http:// www.oie.int/fileadmin/Home/eng/Our_scientific_expertise/docs/pdf/Eng OIE_List_antimicrobials_May2015.pdf (Accessed 14 June 2019).

OIE (World Organization for Animal Health) (2016) The OIE strategy on antimicrobial resistance and the prudent use of antimicrobials, pp. 4-6 [Online]. Available at http://www.oie.int/fileadmin/Home/eng/Media_Center/docs/ pdf/PortailAMR/EN_OIE-AMRstrategy.pdf (Accessed 6 July 2018).

Pardon B, Alliët J, Boone R, Roelandt S, Valgaeren B and Deprez P (2015) Prediction of respiratory disease and diarrhea in veal calves based on immunoglobulin levels and the serostatus for respiratory pathogens measured at arrival. Preventive Veterinary Medicine 120, 169-176.

Pham MT, Rajic A, Greig JD, Sargeant JM, Papadopoulos A and McEwen SA (2014) A scoping review of scoping reviews. Research Synthesis Methods 5, 371-385.

Reinhardt CD and Hubbert ME (2015) Control of liver abscesses in feedlot cattle: a review. The Professional Animal Scientist 31, 101-108.

Ribble CS, Stitt T, Iwasawa S, Toews L and Stephen C (2010) A Review of Alternative Practices to Antimicrobial use for Disease Control in Commercial Feedlots. Winnipeg: National Collaborating Centre for Infectious Diseases, pp. 2-5.

Ryan R, Santesso N and Hill S (2016) Preparing Summary of Findings (SoF) tables. Cochrane Consumers and Communication Group [Online]. Available at http://cccrg.cochrane.org/author-resources. Melbourne. Version 2.0 (Accessed 21 June 2019).

Sanderson MW, Dagatz DA and Wagner BA (2008) Risk factors for initial respiratory disease in United States' feedlots based on producer-collected daily morbidity counts. Canadian Veterinary Journal 49, 373-378.

Sargeant JM, Kelton DF and O'Connor AM (2014) Study designs and systematic reviews of interventions: building evidence across study designs. Zoonoses and Public Health 61(Suppl 1), 10-17.
Sneeringer S, MacDonald J, Key N, McBride W and Mathews K (2015), Economics of Antibiotic Use in U.S. Livestock Production, U.S. Department of Agriculture (USDA), Economic Research Service, ERR-200, pp. 31-37.

Soehnlen MK, Aydin A, Lengerich EJ, Houser BA, Fenton GD, Lysczek HR, Burns CM, Byler LI, Hattel AL, Wolfgang DR and Jayarao BM (2011) Blinded, controlled field trial of two commercially available Mycoplasma bovis bacterin vaccines in veal calves. Vaccine 29, 5347-5354.

Statistics Canada (2018) Farm and Farm Operator Data [Online]. Available at https://www150.statcan.gc.ca/n1/pub/95-640-x/2016001/article/14808-eng. htm (Accessed 21 June 2019).

Stilwell G, Matos M, Carolino N and Lima MS (2008) Effect of a quadrivalent vaccine against respiratory virus on the incidence of respiratory disease in weaned beef calves. Preventive Veterinary Medicine 85, 151-157.

Theurer ME, Larson RL and White BJ (2015) Systematic review and meta-analysis of the effectiveness of commercially available vaccines against bovine herpesvirus, bovine viral diarrhea virus, bovine respiratory syncytial virus, and parainfluenza type 3 virus for mitigation of bovine respiratory disease complex in cattle. Journal of the American Veterinary Medical Association 246, 126-142.

Tricco AC, Lillie E, Zarin W, O'Brien KK, Colquhoun H, Levac D, Moher D, Peters MDJ, Horsley T, Weeks L, Hempel S, Akl EA, Chang C, McGowan J, Stewart L, Hartling L, Aldcroft A, Wilson MG, Garritty C, Lewin S, Godfrey CM, Macdonald MT, Langlois EV, Soares-Weiser K, Moriarty J, Clifford T, Tunçalp Ö and Straus SE (2018) PRISMA Extension for scoping reviews (PRISMA-SCR): checklist and explanation. Annals of Internal Medicine 169, 467-473.

United States Government Accountability Office report US GAO-11-801, September 2011, Antibiotic Resistance.

US FDA (U.S. Food and Drug Administration) (2017) Veterinary Feed Directive Final Rule and next steps, Fact Sheet [Online]. Available at https://www.fda.gov/animal-veterinary/development-approval-process/factsheet-veterinary-feed-directive-final-rule-and-next-steps (Accessed 17 June 2019).

WHO (World Health Organization) (2012) The Evolving Threat of Antimicrobial Resistance. Options for Action. Geneva: WHO Press, pp. 8-9.

WHO (World Health Organization) (2017) WHO Guidelines on Use of Medically Important Antimicrobials in Food-Producing Animals. Geneva: WHO Press, pp. 18-22.

WHO (World Health Organization) (2018) Critically Important Antimicrobials for Human Medicine, 6th Revision. Geneva: WHO Press, pp. $1-13$.

Williams AR, Franke DE, Saxton AM and Turner JW (1990) Two-, threeand four-breed rotational crossbreeding of beef cattle reproductive traits. Journal of Animal Science 68, 1536-1546.

Wilson TB, Faulkner DB and Shike DW (2015) Influence of late gestation drylot rations differing in protein degradability and fat content on beef cow and subsequent calf performance. Journal of Animal Science 93, 5819-5828.

Wisener LV, Sargeant JM, O'Connor AM, Faires MC and Glass-Kaastra SK (2014) The evidentiary value of challenge trial for three pre-harvest food safety topics: a systematic assessment. Zoonoses and Public Health 61, 449-476. 